\title{
La recuperación de lo económico desde el corazón de la economía
}

MoIsÉs GóMEZ

Departamento de Filosofía UCA, San Salvador

En este escrito de homenaje al maestro Aquiles Montoya, me propongo demostrar el profundo carácter humanizante que de la economía tenía este gran cientista social. Ciertamente hay en América Latina, una tradición de pensamiento económico con fuerte acento crítico y consiguientemente, liberador o emancipador como usted guste Ilamarlo. En esa corriente de pensamiento crítico de la economía se inserta el maestro Aquiles con su producción teórica vinculada a sus investigaciones de campo.

\section{El carácter marxista}

I mismo se autodenominaba marxista. Justamente en una de sus contribuciones para el diario digital, ContraPunto ${ }^{1}$ nos explicaba la razón de ello a partir de la respuesta a una simple pregunta: ¿Por qué estudiar a Marx? Y la res- puesta decía que era por un juicio muy sencillo: porque el capitalismo aún existe y para comprender la realidad esencial del modo de producción capitalista. Las características del capitalismo antihumano no solo no han desaparecido, ade- 
más, con la globalización, se han profundizado y extendido al mundo entero: tenemos más desempleo, más desigualdad y los niveles de acumulación de dinero en pocas personas son escandalosos amen del daño ecológico. Como estudioso y conocedor de la obra de Marx, Aquiles había analizado a profundidad y con-ciencia el pensamiento de Marx y de ello concluía la actualidad y vigencia. No era marxista porque compartiera una doctrina anquilosada, ni tampoco era marxista por ser miembro de una estructura político partidaria en el poder que lo protegiera. Era marxista en el sentido de recuperar el pensamiento crítico y emancipador de Marx que se postula, tal como lo señala Hinkelammert, como un pensamiento en términos de resistencia y alternativas frente al poder ${ }^{2}$.

Por otra parte, no creía en cualquier marxismo, sino en aquel marxismo radical. No hay que entender por radical al marxismo ortodoxo. Su radicalidad tiene que ver, en primer lugar, con el respeto intelectual hacia Marx. Ya hemos dicho que no tenía el visto bueno de ningún poder político, tampoco era un simple repetidor de teorías o de autores sino un gran conocedor de Marx del Capital; Aquiles se fue a la fuente primaria: no se quedó en las interpretaciones, fue al tronco y a la raíz de la teoría y no se conformó con la sombra de las ramas que protegen de las críticas. Como cualquier académico riguroso sabía que todo clásico hay que rehacerlo y transformarlo e interpretarlo desde la propia realidad, ahora bien, cuando uno se da a la tarea de reinterpretar y actualizar es susceptible de ser criticado y Aquiles sufrió esta crítica, sabía que eran los gajes del oficio.

En segundo lugar, en su radicalidad hay una opción ética, a partir de su conocimiento de la teoría y de la realidad capitalista; estaba con la firme convicción -en lo teórico y empírico-que el sistema capitalista era inviable para una sociedad más humanizante y por ello no creía en reformas ni en movimientos reformistas del sistema, sino en cambios radicales y por ello necesariamente revolucionarios.

Tampoco creía que ser revolucionario era simplemente cuestión de "darle vuelta a la tortilla" como algunos ingenuos creen de las personas utópicas. Pensaba en la posibilidad de una revolución o cambio "desde abajo", esto es, desde los trabajadores. Y pensaba que desde ellos, en cuanto y en tanto, sujetos se podría llegar a construir una sociedad alternativa a partir de la predominancia del sector trabajo ${ }^{3}$. Se trataba de una idea utópica, pero que es posible Ilevarla a cabo. Es empíricamente posible y no es excluyente como ocurre con la economía capitalista donde se privilegia únicamente la maximización de utilidades a toda costa. En términos de los sujetos del cambio, coincidía con Ignacio 
Ellacuría; aunque específicamente este hablaba de mayorías populares, como sujeto histórico y gestor de una nueva civilización del trabajo ${ }^{4}$.

\section{El fundamento de la economía}

Quiero explicar, antes de proseguir, qué entiendo por lo económico: me refiero a la economía como ámbito de reproducción de la vida humana y de las condiciones que la hacen posible. Cuando se concibe a la economía como el ámbito de la reproducción de la vida humana, lo económico es la reproducción de la vida humana, lo económico no es la eficiencia y/o simplemente aquello que resulte de la competencia entre actores racionales que operan dirigidos por los criterios de la relación entre medios-fines. Para que sea económico, hay que someter el criterio de la racionalidad medio-fin al criterio de la vida-muerte del ser humano. Nuestro pensador llega a concluir que la economía capitalista al absolutizar el valor de la eficiencia y de la competencia que opera como una mano invisible, olvida el fundamento de cualquier valor: el ser humano. Por ello llega a concluir que la economía capitalista no satisface las necesidades humanas y consecuentemente nuestro autor propone una alternativa:

un modelo alternativo de y para las mayorías populares, en los ámbitos económico, social, político, cultural y есоlógico, fundamentado en su propio esfuerzo organizativo y solidario, que tiene como finalidad resolver sus problemas ambientales, de pobreza y exclusión social, tanto en el campo como en la ciudad, y contribuir a la eliminación de las causas que los generan ${ }^{5}$.

Alguno puede preguntarse ¿Cómo es posible que diga que el maestro Aquiles se empeñe en una recuperación de lo económico? ¿No será que en vez de recuperar lo económico trata de recuperar al ser humano de la vorágine capitalista? La respuesta es que no se puede recuperar al ser humano al margen de una institución económica o escindida del Estado por ejemplo. La institución económica no está separada de la condición humana y así fue en el pensamiento humanista hasta el siglo XVIII, cuando se referían a la economía política. Es a partir de ese siglo que la economía es concebida como mera administración de la escasez. Se abandona la responsabilidad de garantizar la vida humana por medio de satisfacer las necesidades que el ser humano como sujeto exige y se enfoca ahora en la pura administración racional de unos recursos escasos frente a una demanda siempre en aumento. Desaparece el ser humano 
como sujeto de necesidades concretas, y en cambio, surge un ser humano como sujeto de preferencias. El profesor Montoya sabía que esa reconceptualización de la economía tuvo consecuencias funestas de cara a la vida humana. Entonces, ahora la pregunta es: ¿Cómo volvemos a una economía más humana, más humanizante? La idea de recuperar o rescatar al ser humano no puede ser tarea de algunos iluminados sino desde él mismo como sujeto de una praxis inhumana, es el mismo sujeto oprimido el que tiene que gestionar su propia recuperación y dignificación creando nuevas formas de relacionarse socialmente en un nuevo proyecto de sociedad y economía que don Aquiles Ilamaba economía solidaria. Afirmaba que en nuestro país y en varios lugares del mundo actual existen experiencias ${ }^{6}$ que poseen elementos propios de aquella economía: asociatividad, autogestión, solidaridad, propiedad asociativa y racionalidad económica reproductiva ${ }^{7}$.

\section{Un ejercicio intelectual que da esperanza}

Nuestro autor homenajeado se inserta en esa tradición de pensadores que, siendo muy realistas, no cayeron en el error de socavar el carácter utópico del ser humano; no obstante, Aquiles vivió en la profundidad de la cultura de la desesperanza, cuyo rasgo principal es que ha perdido la capacidad de pensar un mundo mejor y que por oposición, propone la total aceptación de la realidad del mercado y la actual organización económica, por ejemplo Dahl:

Durante los dos últimos siglos, socialistas, planificadores, tecnócratas y muchos otros alimentaron visiones en las que los mercados serían amplia y permanentemente reemplazados por procesos más justos, mejor ordenados y planificados, de toma de decisiones económicas sobre la producción, el establecimiento de los precios, y la distribución de bienes y servicios. Estas visiones prácticamente se han desvanecidos en el olvido. Con independencia de los defectos que pueda tener una economía de mercado, parece ser la única opción para los países democráticos en el nuevo siglo ${ }^{8}$.

El profesor Montoya nunca se creyó este discurso ideológico cuya pretensión es hacernos creer que no hay más alternativa para las sociedades democráticas que terminar siendo sociedades de mercado. Lo cual es un absurdo, como bien apuntaba otro gran académico, el padre lbisate, que insistía que puede haber economías de mercado pero nunca sociedades de mercado dado que, además de los mercados, la sociedad necesita instituciones con fines sociales como la libertad política y la justicia social ${ }^{9}$. 
Es un hecho que desde la visión conservadora de la sociedad y de la economía hemos alcanzado lo que Fukuyama tildó como el fin de la historia ${ }^{10}$ : no hay más allá de la economía capitalista de mercado. Pese a que hay una tensión creciente entre la democracia y aquella economía, de acuerdo al pensamiento conservador, la balanza ya se inclinó a favor del mercado y la democracia debe adaptarse a esa condición sine qua non. En medio de tanto pesimismo utópico el maestro Montoya se aferró a la idea de que las cosas podían cambiarse procesualmente desde abajo. Desde la propia raíz del sistema: el sujeto humano y su fuerza de trabajo. Los innumerables trabajos que publicó en revistas nacionales e internacionales, sus textos y otras contribuciones tienen todos ellos una característica: generar es-

Notas

1. Montoya, A. "¿Por qué estudiar a Marx?” En ContraPunto, edición del 22 de febrero 2011. En línea: http://www.contrapunto.com.sv/columnistas/por-que-estudiar-a-marx

2. Hinkelammert, F. El nibilismo al desnudo. Los tiempos de la globalización. Ed. LOM, Santiago de Chile, 2001. Pág. 259-260.

3. Cf. Departamento de Economía (UCA): Economía solidaria. Grupo Bajo Lempa. Editorial: sin identificación, San Salvador, 2005. Pág. 1-2.

4. Ver para este punto especialmente Montoya, A. La nueva economía peranza en un ambiente intelectual desesperanzador que construye la realidad social con anteojos que sólo ven economía capitalista. En realidad, Aquiles descubrió que había importantes ejercicios de economía solidaria y se invisibilizan. En sus escritos las referencias a praxis típicas de economía solidaria abundaban: en el Bajo Lempa, en parroquias como Calle Real, San Bartolo, en la Chacra, en Guazapa, en San Miguel; en el área internacional, menciona Singapur, Chile, Brasil, Colombia y Nicaragua; por mencionar algunos de los lugares donde concretamente hay brotes, gérmenes de esta nueva configuración económica. Ojalá que las generaciones de economistas que coadyuvó a formar retomen su legado intelectual al servicio de la construcción de una sociedad más justa, más solidaria.

popular. Una aproximación teórica. UCA. Ed. San Salvador, 1993. Pág. 46-47.

5. Ibíd. Pág. 42

6. Ver: Montoya, A. La nueva economía popular. Una aproximación empirica. UCA. Ed. San Salvador, 1994. Págs. 13 a 108.

7. Cf. Departamento de Economía (UCA): Economía solidaria. Grupo Bajo Lempa. Pp. 16-22.

8. Dahl, R. La democracia. Una guía para los ciudadanos. Taurus, Madrid, 1999. Pág. 204-205. 
9. Ibisate, F. J.: "La estrecha ruta hacia la globalización de la solidaridad" Estudios Centroamericanos ECA, 673-674, UCA Ed., San Salvador, 2004, pág. 1262.
10. Ver: Fukuyama, F. "The end of History", Revista The National Interest, 1989. 